\title{
Transient Stability Assessment by using Critical Trajectory Method for Smart Grid System
}

\author{
${ }^{1}$ Isa Hafidz, ${ }^{2}$ Ardyono Priyadi and ${ }^{3}$ Naoto Yorino \\ ${ }^{1}$ Department of Electrical Engineering, Institut Teknologi Telkom Surabaya, Gayungan, \\ 60231 Surabaya, Indonesia \\ ${ }^{2}$ Department of Electrical Engineering, Institut Teknologi Sepuluh Nopember ITS, Keputih, Sukolilo, \\ 60111 Surabaya, Indonesia \\ ${ }^{3}$ Hiroshima University, 1-4-1 Kagamiyama, 739-8527 Higashihiroshima, Japan \\ isa@ittelkom-sby.ac.id
}

\begin{abstract}
Transient stability assessment is needed to get an analysis of the power system stability. This critical period occurs when generator experiences a condition of lossing synchronization and is known as critical time. The smartgrid system, currently becoming a trend, requires dynamic optimization and realtime measurement techniques, so that, it can improve system reliability and asset management. In this study, the researcher modifies critical trajectory method to obtain a critical period of smartgrid system. Simulations are carried out using the Anderson 9-bus Fouad and IEEE 30-bus test systems. The results indicate that the proposed method can more quickly solve calculations compared to conventional methods. Some of our results are not intuitive.
\end{abstract}

Key words: Transient stability assessment, critical clearing time, loss of synchronization, smart grid system, simulations, results indicate

\section{INTRODUCTION}

The concept of smart grid system is designed to improve safety, economy and efficiency, so that, the complexity of operation of power systems can be overcome (Kundur et al., 2004). Transient stability study is related to ability of the power system to maintain synchronous conditions due to transient disturbances (Ramirez and Villafuerte, 2016; Athay et al., 1979). Response to the system can affect the magnitude of deviations at rotor angle of generator. Transient stability is categorized as a short-term phenomenon. Time limits for transient stability are limited to $3-5 \mathrm{sec}$ after disturbance.

There are many calculation methods to transient stability assessment. Dynamic phasors and direct method of Lyapunov are studied methods for application in power systems. Numerical simulation method, called time domain simulation is used to analyze system, starting from initialization of starting point to get a dynamic response from fault. This method can easily calculate varies model of complex power systems (Athey et al., 1979; Madruga et al., 2018) and representative when studying the generation stability. However, it has a deficiency which is more time consuming in calculation and it needs to evaluate voltage and frequency imposed to the loads, so that, it is not satisfactory and not suitable when applied to calculations in real time. Probabilistic and artificial intelligence method also has been developed to predict Critical Clearing Time (CCT) for on-line double circuit power system (Sulistiawati et al., 2016; James et al., 2018). A training technique is used in this method (Pagani and Aiello, 2016).

An alternative approach is by using energy function method (Shi et al., 2012; Irisarri et al., 1994). This method learns about the stability of the power system by considering energy of the system which is calculated from nonlinear relationships when critical period (Chiang et al., 1994; Treinen et al., 1996). The energy function is a powerful tool for assessing stability of a power system. It also can analyze energy margin sensitivity and power system stability degree quantitatively. However, this method has a deficiency in terms of accuracy. This problem is caused by determination of complicated calculations due to the critical energy calculations. A new method called critical trajectory is used by using minimization problem for computing critical trajectory (Yorino et al., 2005;

Corresponding Author: Isa Hafidz, Department of Electrical Engineering, Institut Teknologi Telkom Surabaya, Gayungan, 60231 Surabaya, Indonesia, isa@ittelkom-sby.ac.id 
Naoto et al., 2008). Critical conditions with CCT for transient stability are directly computed as solution of minimization problem, based on preliminary examinations. Yet, the test result still limited in double parallel circuits in large system.

Since, the behavior of power system is continuously changing, research of centralized operations and control of large-scale systems is a challenging task (De Oliveira et al., 2018). To overcome these challenges, use of the latest information and communication technology networks is urgently needed. This opportunity, motivates concept of operation and control of conventional power systems to be more intelligent system, either in peer-to-peer or distributed multi-agent method. The smartgrid concept forms a new dimension of conventional power system operating systems and also increases the complexity of smart devices. This system promises to revolutionize energy sector with real-time information, renewable power resource penetration and more efficiency (Rahman et al., 2015, 2012; Mahmud et al., 2014). The systems related to the architecture of the smartgrid system which includes control generators, protection imposed and electrical loads connected to transmission networks (Machowski et al., 1997; Adnan et al., 2019). With technological advancements, development updated, the use of Distributed Generation (DG) is also increasing. Although, this can cause an unstable operating system (De Oliveira-De Jesus and Antunes, 2018).

In this study, time domain simulation method is adopted to analyze the interactions in smart grid system and modified critical trajectory method is applied to improve the transient stability assessment of power system with fast integration and high accuracy.

\section{MATERIALS AND METHODS}

\section{Problem formulation}

Power flow studies by using modified Newton Raphson: In modified newton method (Kebaili et al., 2001; Zhang and Cheng, 1997), elements of Jacobian matrices, branchs, generators and buses are under the following assumptions: small voltage differences between two nodes are not considered because of shunt branches. The first assumption above is valid because the typical distribution channel is short and the flowing power is not high. The second assumption is invalid, if there is a bank capacitor, load impedance and non-negligible shunt admittance from the channel distribution model (Model Z). However, by using initial and updated node voltage, all the shunt branches can be converted to node power injections. These conversion have been implemented in all fast decoupled and back/forwards sweep methods. Power flow problem in classical Newton:

$$
\left[\begin{array}{cc}
\mathrm{H} & \mathrm{N} \\
\mathrm{J} & \mathrm{L}
\end{array}\right]\left[\begin{array}{c}
\Delta \theta \\
\frac{\Delta \mathrm{V}}{\mathrm{V}}
\end{array}\right]=\left[\begin{array}{c}
\Delta \mathrm{P} \\
\Delta \mathrm{Q}
\end{array}\right]
$$

Where:

$\mathrm{P}(\mathrm{Q}) \quad=$ Active power

- $\mathrm{P}(\bullet \mathrm{Q}) \quad=$ Power mismatch

$\mathrm{P}(\mathrm{Q}), \cdot(\mathrm{V})=$ Nodal voltage angle magnitude vector

$\cdots(\bullet \mathrm{V})=$ Correction vector

$\mathrm{H}, \mathrm{N}, \mathrm{J}, \mathrm{L}=$ Jacobian matrices

$$
\begin{aligned}
& \mathrm{H}_{\mathrm{ij}}=-\mathrm{V}_{\mathrm{i}} \mathrm{V}_{\mathrm{j}}\left(\mathrm{G}_{\mathrm{ij}} \sin \theta_{\mathrm{ij}}-\mathrm{B}_{\mathrm{ij}} \cos \theta_{\mathrm{ij}}\right) \mathrm{j} \neq \mathrm{i} \\
& \mathrm{H}_{\mathrm{ii}}=\mathrm{V}_{\mathrm{i}} \sum_{\mathrm{j} \in \mathrm{i}, \mathrm{j \neq i}} \mathrm{Vj}\left(\mathrm{G}_{\mathrm{ij}} \sin \theta_{\mathrm{ij}}-\mathrm{B}_{\mathrm{ij}} \cos \theta_{\mathrm{ij}}\right) \\
& N_{i j}=-V_{i} V_{j}\left(G_{i j} \cos \theta_{i j}-B_{i j} \sin \theta_{i j}\right) j \neq i \\
& \mathrm{H}_{\mathrm{ii}}=-\mathrm{V}_{\mathrm{i}} \sum_{\mathrm{j} \in \mathrm{i}, \mathrm{j} \neq \mathrm{i}} \mathrm{V}_{\mathrm{j}}\left(\mathrm{G}_{\mathrm{ij}} \cos \theta_{\mathrm{ij}}-\mathrm{B}_{\mathrm{ij}} \sin \theta_{\mathrm{ij}}\right)-2 \mathrm{~V}_{\mathrm{i}}^{2} \mathrm{G}_{\mathrm{ii}} \\
& \mathrm{J}_{\mathrm{ij}}=\mathrm{V}_{\mathrm{i}} \mathrm{V}_{\mathrm{j}}\left(\mathrm{G}_{\mathrm{ij}} \cos \theta_{\mathrm{ij}}-\mathrm{B}_{\mathrm{ij}} \sin \theta_{\mathrm{ij}}\right) \mathrm{j} \neq \mathrm{i} \\
& \mathrm{J}_{\mathrm{ii}}=-\mathrm{V}_{\mathrm{i}} \sum_{\mathrm{j} \in \mathrm{i}, \mathrm{j} \neq \mathrm{i}} \mathrm{V}_{\mathrm{j}}\left(\mathrm{G}_{\mathrm{ij}} \cos \theta_{\mathrm{ij}}-\mathrm{B}_{\mathrm{ij}} \sin \theta_{\mathrm{ij}}\right) \\
& L_{i j}=-V_{i} V_{j}\left(G_{i j} \cos \theta_{i j}-B_{i j} \sin \theta_{i j}\right) j \neq i \\
& L_{i i}=-V_{i} \sum_{j \in i, j \neq i} V_{j}\left(G_{i j} \cos \theta_{i j}-B_{i j} \sin \theta_{i j}\right)+2 V_{i}^{2} G_{i i}
\end{aligned}
$$

In Eq. 2, variable $\mathrm{G}_{\mathrm{ij}}+\mathrm{jB}_{\mathrm{ij}}$ is entry of nodal admittance matrix. Since, voltage difference between two adjenct nodes is small and it show that matrices $\mathrm{H}, \mathrm{N}, \mathrm{J}$ and $\mathrm{L}$ have same properties (symmetry, sparsity pattern) as nodal admittance matrix, hence, they can be formulated as:

$$
\begin{aligned}
& \mathrm{H}=\mathrm{L}=\mathrm{A}_{\mathrm{n}-1} \mathrm{D}_{\mathrm{B}} \mathrm{A}^{\mathrm{T}}{ }_{\mathrm{n}-1} \\
& \mathrm{~J}=-\mathrm{N}=\mathrm{A}_{\mathrm{n}-1} \mathrm{D}_{\mathrm{G}} \mathrm{A}_{\mathrm{n}-1}^{\mathrm{T}}
\end{aligned}
$$

where, $D_{B}$ and $D_{G}$ are diagonal matrices with diagonal entries to be $V_{i} V_{j} B_{i j} \cos { }^{\bullet}{ }_{i j}$ and $V_{i} V_{j} G_{i j} \cos \bullet_{i j}$. Thus, the equation can be written as:

$$
\left[\begin{array}{cc}
\mathrm{A}_{\mathrm{n}-1} & 0 \\
0 & \mathrm{~A}_{\mathrm{n}-1}
\end{array}\right] \cdot\left[\begin{array}{cc}
\mathrm{D}_{\mathrm{B}} & -\mathrm{D}_{\mathrm{G}} \\
\mathrm{D}_{\mathrm{G}} & \mathrm{D}_{\mathrm{B}}
\end{array}\right] \cdot\left[\begin{array}{cc}
\mathrm{A}_{\mathrm{n}-1}^{\mathrm{T}} & 0 \\
0 & \mathrm{~A}_{\mathrm{n}-1}^{\mathrm{T}}
\end{array}\right] \cdot\left[\begin{array}{c}
\Delta \theta \\
\frac{\Delta \mathrm{V}}{\mathrm{V}}
\end{array}\right]=\left[\begin{array}{c}
\Delta \mathrm{P} \\
\Delta \mathrm{Q}
\end{array}\right]
$$

$A_{n-1}$ is an upper triagular matrix with all diagonal entries is valued 1 and all non-zero off diagonal entries to be-1. The principle of each node is to imitate the concept of the root node. Node ordering is used continuously, the branch of the node is equal to the number of branch numbers. Following complex is form as follows: 


$$
A_{n-1}=\left[\begin{array}{cccccccccc}
1 & & -1 & -1 & & & & & \\
& & & & & -1 & & & & \\
& & 1 & & & & & & \\
& & & 1 & & -1 & & & \\
& & & & 1 & & -1 & -1 & \\
& & & & & 1 & & & \\
& & & & & & 1 & & \\
& & & & & & & & \\
& & & & & & 1 & -1 \\
& & & & & & & & & \\
& & & & & & & & 1
\end{array}\right]
$$

Jacobian matrix can be formed as product of three square matrices which has same concept as nodal admittance matrix in Eq. 5. Then, Eq. 4 can be solved by back/forward sweeps:

$$
\mathrm{A}_{\mathrm{n}-1} \dot{\mathrm{W}} \mathrm{A}_{\mathrm{n}-1}^{\mathrm{T}} \dot{\mathrm{E}}=\dot{\mathrm{S}}
$$

Where:

$$
\begin{aligned}
& \dot{\mathrm{E}}=\Delta \theta+\mathrm{j} \frac{\Delta \mathrm{v}}{\mathrm{v}} \\
& \dot{\mathrm{S}}=\Delta \mathrm{P}+\mathrm{j} \Delta \mathrm{Q} \\
& \dot{\mathrm{W}}=\mathrm{D}_{\mathrm{B}}+\mathrm{j} \mathrm{D}_{\mathrm{G}}
\end{aligned}
$$

To solve • in Eq. 6 in forward sweep, diagonal matrix $\dot{w}$ can be inverted for each line. Diagonal in $\mathrm{W}^{-1}$ is denoted as the equivalent line impedance $Z_{\text {eq }}$ by summation of $R_{e q}$ and $\mathrm{j} \mathrm{X}_{\text {eq }}$ This concept is simulated and used by researcher to compare between proposed method and simulation method.

Critical trajectory: Critical trajectory method is a new formulation for transient stability assessment for power systems (Yorino et al., 2010). A minimization problem is formulated for obtaining CCT based on the computation of a trajectory on stability boundary this is useful to explain the dynamic response of the generator, starting from before until after the disturbance. The power system is used to operate with normal and stable conditions at $\mathrm{x}_{\text {pre }}$ and fault occurs at $\mathrm{t}=0$ and cleared at $\mathrm{t}=\boldsymbol{\bullet}$. The response experienced by the system can be explained in Eq. 10 :

$$
\dot{\mathrm{x}}=\mathrm{f}_{\mathrm{F}}(\mathrm{x}), 0 \leq \mathrm{t} \leq \tau, \mathrm{x}(0)=\mathrm{x}_{\mathrm{pre}}
$$

where, $x \cdot R^{N}, t \cdot R, f_{F}: R^{N} \bullet R^{N}$. Equation 10 is developed to formulate fault on trajectory or trajectory 1 in Eq. 11 :

$$
\mathrm{x}(\mathrm{t})=\mathrm{X}_{\mathrm{F}}\left(\mathrm{t} ; \mathrm{x}_{\text {pre }}\right), 0 \leq \mathrm{t} \leq \tau, \mathrm{X}_{\mathrm{F}}\left(; \mathrm{x}_{\mathrm{pre}}\right): \mathrm{R} \rightarrow \mathrm{R}^{\mathrm{N}}
$$

There is an initial point in fault on trajectory named $\mathrm{x}^{0}$ at time - when the fault is over:

$$
\mathrm{X}^{0}=\mathrm{X}_{\mathrm{F}}\left(\tau, \mathrm{X}_{\mathrm{pre}}\right)
$$

The state of post-fault condition is described into (Eq. 13) and then developed into (Eq. 14):

$$
\begin{gathered}
\dot{\mathrm{x}}=\mathrm{f}(\mathrm{x}), \tau \leq \mathrm{t} \leq \infty ; \mathrm{f}: \mathrm{R}^{\mathrm{N}} \rightarrow \mathrm{R}^{\mathrm{N}} \\
\mathrm{x}(\mathrm{t})=\mathrm{X}\left(\mathrm{t} ; \mathrm{x}^{0}\right), \pi \leq \mathrm{t} \leq \infty ; \mathrm{X}\left(; \mathrm{x}^{0}: \mathrm{R} \rightarrow \mathrm{R}^{\mathrm{N}}\right)
\end{gathered}
$$

Critical trajectory method is defined as trajectory from fault to the moment before generator occur loss of synchronization. This trajectory will describes critical state and reach the Unstable Equilibrium Point (UEP). During stable state before generator loses synchronization, trajectory oscillates around Stable Equilibrium Point (SEP). Unstable condition happen when disturbance is late to overcome.

The search for CCT values starts from the initial value to critical point and it is limited between $x^{0}$ and $x^{u}$. To avoid unlimited searches, trapezoidal equation has been modified for numerical processing as in condition $\mathrm{x}^{\mathrm{k}} \cdot \mathrm{R}^{\mathrm{N}}$, $\bullet \mathrm{R}, \cdots \mathrm{R}$ (Eq. 15) where, $\mathrm{k}$ notation is used to express the movement of time:

$$
\mathrm{x}^{\mathrm{k}+1}-\mathrm{x}^{\mathrm{k}}-\frac{\dot{\mathrm{x}}^{\mathrm{k}+1}+\dot{\mathrm{x}}^{\mathrm{k}}}{\left|\dot{\mathrm{x}}^{\mathrm{k}+1}+\dot{\mathrm{x}}^{\mathrm{k}}\right|} \varepsilon=0
$$

End point formulation: Boundaries of the critical trajectory can be written as in Eq. 15 :

$$
G(x)=\left\{\begin{array}{l}
x^{0}=X_{F}\left(\text { CCT }: x_{p r e}\right)=0 \\
\mu^{m+1}=\left[\frac{\partial p^{m+1}}{\partial \theta^{m+1}} \cdot v\right]
\end{array}\right.
$$

Variable needed to be searched during calculation process can be written in Eq. 17:

$$
X=\left(x^{0}, x^{1}, \ldots, x^{m}, x^{m+1}, \varepsilon, \tau\right)
$$

End point of the search representing a stationary condition for power synchronization and torque. This condition can be written as $\dot{\mathrm{P}}=0$ where, $\dot{\mathrm{P}}$ is a function of the rotor generator with Eq. 18:

$$
\dot{\mathrm{P}}=\frac{\partial \mathrm{P}}{\partial \theta} \dot{\theta}
$$


In modified of loss of synchronization method (Eq. 18), determination of value of the end point, the value and direction of the eigenvector of - against UEP position is not considered. Therefore, value of constant - and $\mathrm{k}$, a parameter value in the eigenvector is not considered in next calculation process.

Numerical examination: Numerical examination is used to reprresent two dimensional differential equations of generator by calculating $\mathrm{Xd}$ '. First swing equation, considering damping is formulated in Eq. 19:

$$
\frac{\mathrm{M}}{\omega_{\mathrm{s}}} \dot{\omega}=\mathrm{P}_{\mathrm{m}}-\mathrm{P}_{\mathrm{e}}-\frac{\mathrm{D}}{\omega_{\mathrm{s}}} \omega
$$

In systems with more than one generator, it is important for rotor angles and rotor speeds having a reference as the center of mass of the rotor angle or rotor speed all generators. This reference is called Center of Inertia (COI). COI can be formulated as Eq. 20:

$$
\mathrm{M}_{\mathrm{T}} \cdot \delta_{0}=\sum_{\mathrm{i}=1}^{\mathrm{n}} \mathrm{M}_{\mathrm{i}} \cdot \delta_{\mathrm{i}}
$$

Since, $\ddot{\delta}=\dot{\omega}$ (Eq. 20) can be written as Eq. 21 :

$$
\mathrm{M}_{\mathrm{T}} \cdot \dot{\omega}_{0}=\sum_{\mathrm{i}=1}^{\mathrm{n}} \mathrm{M}_{\mathrm{i}} \cdot \dot{\omega}_{\mathrm{i}}=\mathrm{P}_{\mathrm{COI}}
$$

Since, $\mathrm{M}_{\mathrm{T}}=\sum_{\mathrm{i}=1}^{n} \mathrm{M}_{\mathrm{i}}$ reference of COI can be obtained as in Eq. 21. For case calculation in each rotor angle and speed, a new value is obtained by using the COI reference as in Eq. 22 and 23. The Center of Inertia (COI) swing equation is carried out for both the conventional numerical simulation and the proposed method.

$$
\mathrm{M}_{\mathrm{i}} \dot{\tilde{\omega}}_{\mathrm{i}}=\mathrm{P}_{\mathrm{mi}}-\mathrm{P}_{\mathrm{ei}}(\theta)-\frac{\mathrm{M}_{\mathrm{i}}}{\mathrm{M}_{\mathrm{T}}} \cdot \mathrm{P}_{\mathrm{COI}}-\mathrm{D}_{\mathrm{i}}\left(\dot{\tilde{\omega}}_{\mathrm{i}}\right)
$$

Where:

$$
\dot{\omega}_{0}=\frac{1}{\mathrm{M}_{\mathrm{T}}} \mathrm{P}_{\text {COI }} ; \tilde{\omega}_{1}=\omega_{1}-\omega_{0} ; \theta_{\mathrm{i}}=\delta_{\mathrm{i}}-\delta_{0}
$$

The system tested is a distribution system loop and radial configuration with single circuit. Single circuit system can not supply power when fault occurs while double circuit system still can transfer power. This causes reactance value of the system $(\mathrm{x})$ is different between one circuit and two circuits in each state both in pre and post fault. Therefore, current values and sytem stability response will be different.

\section{RESULTS AND DISCUSSION}

Simulation and analysis: System used for simulations are Fouad anderson and IEEE 16 bus and 30 bus as shown in Fig. 1. This plan is modified by the researcher to make radial distribution system and consist of single transmission line as implemented in smartgrid system. Circuit Breaker (CB) at each end of transmisssion line, located near the bus can open to eliminating disturbance.

Simualtion is done on several fault locations in each system. Table 1 and 2 show the simulation results for loop system while Table 3 and 4 for radial system.

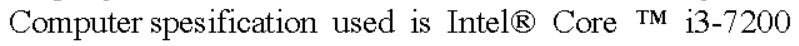
U CPU $2.71 \mathrm{GHz}$ hardware, 6.00 GB RAM and Windows 10 as the operating system.

Fault type is assumed a three phase fault to the ground and occurs near bus. The simulation uses 4th Runge-Kutta as the strongest numeric with the time step used $0.001 \mathrm{sec}$. After that, the initial condition - which has been chosen is used numerically to obtain accurate results. Furthermore, the time of CCT lies in period of stable and unstable conditions of system.

In online detection systems such as Smart Grid, generator selection, stability calculation and information transmission process takes about $150 \mathrm{msec}$ after interruption. Therefore, a modified method is needed to determine stability of system with a fast calculation. The system will regain its stability, if disturbances are handled by opening $\mathrm{CB}$ before critical breaking time or known as Critical Clearing Time (CCT). When generator cannot be stable until the critical time limit, loss of syncronization condition occur.

Figure 2 illustrates comparison between stable and unstable period from simulation method. This fig also describe relationship between velocity and rotor angle which it is become the subject of this study. Proposed

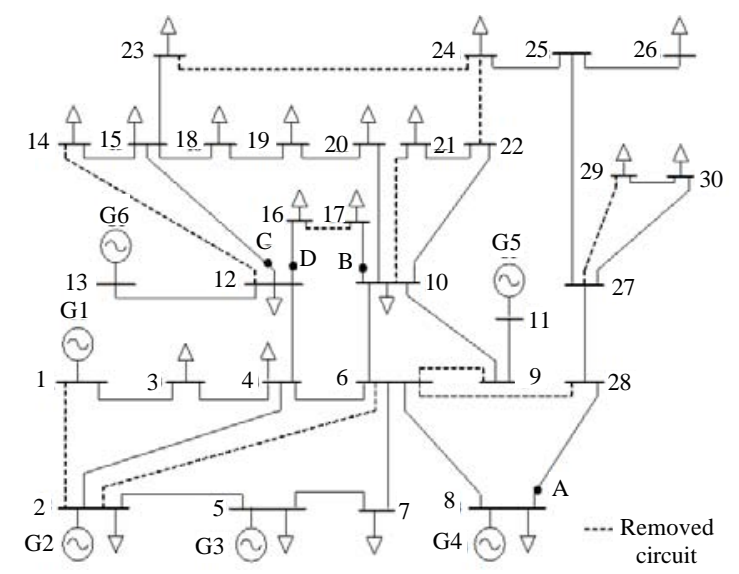

Fig. 1: Modified IEEE 30 bus system 
Table 1: CCT value on Fouad Anderson 3 generator 9 bus without damping by using COA calculation

\begin{tabular}{|c|c|c|c|c|c|c|}
\hline \multirow[b]{2}{*}{ Fault points } & \multirow[b]{2}{*}{ Open line } & \multicolumn{3}{|c|}{ Proposed method } & \multicolumn{2}{|c|}{ Simulation method } \\
\hline & & $\mathrm{CCT}(\mathrm{sec})$ & $\mathrm{CPU}(\mathrm{sec})$ & $\mathrm{CG}$ & $\mathrm{CCT}(\mathrm{sec})$ & $\mathrm{CPU}(\mathrm{sec})$ \\
\hline A & $4-5$ & 0.2101 & 0.4365 & $\mathrm{G} 2$ & $0.24-0.25$ & 1.3860 \\
\hline B & $4-6$ & 0.2130 & 0.1884 & G3 & $0.24-0.25$ & 0.9201 \\
\hline $\mathrm{C}$ & $7-5$ & 0.3825 & 0.5644 & $\mathrm{G} 2$ & $0.38-0.39$ & 1.5287 \\
\hline D & $7-8$ & 0.5890 & 0.3195 & $\mathrm{G} 2$ & $0.59-0.60$ & 1.0268 \\
\hline $\mathrm{E}$ & $9-6$ & 0.2410 & 0.2970 & G3 & $0.24-0.25$ & 1.0080 \\
\hline $\mathrm{F}$ & $9-8$ & 0.2368 & 0.3025 & G3 & $0.25-0.26$ & 1.0120 \\
\hline
\end{tabular}

Table 2: CCT value on Fouad Anderson 3 generator 9 bus with damping by using COA calculation

\begin{tabular}{|c|c|c|c|c|c|c|}
\hline \multirow[b]{2}{*}{ Fault points } & \multirow[b]{2}{*}{ Open lines } & \multicolumn{3}{|c|}{ Proposed method } & \multicolumn{2}{|c|}{ Simulation method } \\
\hline & & $\mathrm{CCT}(\mathrm{sec})$ & $\mathrm{CG}$ & $\mathrm{CPU}(\mathrm{sec})$ & $\mathrm{CCT}(\mathrm{sec})$ & $\mathrm{CPU}(\mathrm{sec})$ \\
\hline A & $4-5$ & 1.6720 & 0.290 & G2 & $1.57-1.58$ & 1.2853 \\
\hline B & $4-6$ & 1.0520 & 0.355 & G3 & $1.1-1.110$ & 1.3150 \\
\hline $\mathrm{C}$ & $7-5$ & 1.0042 & 0.377 & $\mathrm{G} 2$ & $1.0-1.010$ & 1.3050 \\
\hline D & $7-8$ & 0.7877 & 0.282 & $\mathrm{G} 2$ & $0.74-0.75$ & 0.2829 \\
\hline $\mathrm{E}$ & $9-6$ & 0.7280 & 0.351 & G3 & $0.76-0.77$ & 1.2660 \\
\hline $\mathrm{F}$ & $9-8$ & 0.6550 & 0.345 & G3 & $0.75-0.76$ & 1.2958 \\
\hline
\end{tabular}

Table 3: Simulation of proposed method at modified IEEE 6 generator 30 bus without damping by using COA calculation

\begin{tabular}{|c|c|c|c|c|c|c|}
\hline \multirow[b]{2}{*}{ Fault points } & \multirow[b]{2}{*}{ Open lines } & \multicolumn{3}{|c|}{ Proposed method } & \multicolumn{2}{|c|}{ Simulation method } \\
\hline & & $\mathrm{CCT}(\mathrm{sec})$ & $\mathrm{CPU}(\mathrm{sec})$ & $\mathrm{CG}$ & $\mathrm{CCT}(\mathrm{sec})$ & $\mathrm{CPU}(\mathrm{sec})$ \\
\hline$\overline{\mathrm{A}}$ & $8-28$ & 1.7000 & 0.9846 & G3 & $1.7-1.8$ & 2.5925 \\
\hline B & $4-12$ & 0.2234 & 0.3804 & G5 & $0.21-0.22$ & 1.9385 \\
\hline $\mathrm{C}$ & $6-9$ & 0.2024 & 0.4429 & G5 & $0.26-0.27$ & 3.3572 \\
\hline $\mathrm{D}$ & $6-10$ & 0.2946 & 0.6460 & G6 & $0.30-0.0 .31$ & 2.7214 \\
\hline $\mathrm{E}$ & $4-6$ & 0.2463 & 1.8913 & G5 & $0.23-0.24$ & 8.2352 \\
\hline
\end{tabular}

Table 4: Simulation of proposed method at modified IEEE 6 generator 30 bus with damping by using COA calculation

\begin{tabular}{|c|c|c|c|c|c|c|}
\hline \multirow[b]{2}{*}{ Fault points } & \multirow[b]{2}{*}{ Open lines } & \multicolumn{3}{|c|}{ Proposed method } & \multicolumn{2}{|c|}{ Simulation method } \\
\hline & & $\mathrm{CCT}(\mathrm{sec})$ & $\mathrm{CPU}(\mathrm{sec})$ & $\mathrm{CG}$ & $\mathrm{CCT}(\mathrm{sec})$ & $\mathrm{CPU}(\mathrm{sec})$ \\
\hline $\mathrm{D}$ & $6-10$ & 0.4034 & 0.6623 & G6 & $0.4-0.41$ & 3.5951 \\
\hline $\mathrm{E}$ & $4-6$ & 0.1451 & 0.7041 & G5 & $0.18-0.19$ & 5.0412 \\
\hline
\end{tabular}

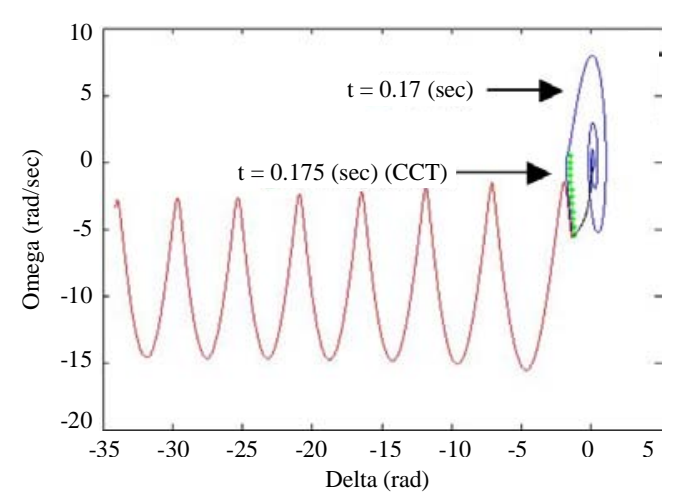

Fig. 2: Angular velocity and rotor angle of generator 4 (G4) in modified IEEE 30 bus at fault point "A"

method, lossing synchronization, provide exact value of CCT. There are two values where $0.17 \mathrm{sec}$, located at the lower limit, explains the stable condition. Whereas $0.18 \mathrm{sec}$, located at upper limit, explains the unstable condition. The exact CCT value is searched by using proposed and modified method, then $0.175 \mathrm{sec}$. Table 1 and 2 show CCT values found with modification method compared with conventional methods.

Table 1-4 showed that average CPU speed to set the value of $\mathrm{CCT}$ at any point of disturbance of $0.333 \mathrm{sec}$ by addition of damping and average error $0.430 \%$. Average error by using the proposed method in IEEE 3-generator 33-bus system is $0.393 \%$ by using damping on the generator model. IEEE 6-generator 30-bus system shows average error using a proposed method of $0.869 \%$ for systems using COA reference without damping.

\section{CONCLUSION}

Transient stability assessment is needed to determine the stability of ystem when experiencing large disturbances such as short circuit. This affects critical period of generator to be able to maintain and restore system stability. Simulation to look for critical time, known as CCT has been done to compare modifications to the critical trajectory method with conventional methods. 
Experiments that have been carried out prove that the proposed method is accurate by using a modified trapezoidal equation. In addition, this method also has a faster counting process. This indicates that the average CPU speed can be used to justify transient stability in smartgrid system.

\section{REFERENCES}

Adnan, M., M. Tariq, Z. Zhou and H.V. Poor, 2019. Load flow balancing and transient stability analysis in renewable integrated power grids. Intl. J. Electr. Power Energy Syst., 104: 744-771.

Athay, T., R. Podmore and S. Virmani, 1979. A practical method for the direct analysis of transient stability. IEEE. Trans. Power Apparatus Syst., 98: 573-584.

Chiang, H.D., F.F. Wu and P.P. Varaiya, 1994. A BCU method for direct analysis of power system transient stability. IEEE. Trans. Power Syst., 9: 1194-1208.

De Oliveira-De Jesus, P.M. and C.H. Antunes, 2018. Economic valuation of smart grid investments on electricity markets. Sustainable Energy Grids Netw., 16: 70-90.

Irisarri, G.D., G.C. Ejebe, J.G. Waight and W.F. Tinney, 1994. Efficient solution for equilibrium points in transient energy function analysis. IEEE. Trans. Power Syst., 9: 693-699.

James, J.Q., D.J. Hill and A.Y. Lam, 2018. Delay aware transient stability assessment with synchrophasor recovery and prediction framework. Neurocomputing, 322: 187-194.

Kebaili, S., F. Adjeroud and K. Zehar, 2001. Extension of the modified Newton method for radial distribution systems load flow. Proceedings of the International Canadian Conference on Electrical and Computer Engineering 2001 (Cat. No. 01 TH8555) Vol. 2, May 1316, 2001, IEEE, Toronto, Ontario, Canada, pp: 781-784.

Kundur, P., J. Paserba, V. Ajjarapu, G. Andersson and A. Bose et al., 2004. Definition and classification of power system stability IEEE/CIGRE joint task force on stability terms and definitions. IEEE Trans. Power Syst., 19: 1387-1401.

Machowski, J., J.W. Bialek and R.J. Bumby, 1997. Power System Dynamics and Stability. John Wiley and Sons, Ltd., New York.

Madruga, E.P., D.P. Bernardon, R.P. Vieira and L.L. Pfitscher, 2018. Analysis of transient stability in distribution systems with distributed generation. Intl. J. Electr. Power Energy Syst., 99: 555-565.

Mahmud, M.A., H.R. Pota, M. Aldeen and M.J. Hossain, 2014. Partial feedback linearizing excitation controller for multimachine power systems to improve transient stability. IEEE. Trans. Power Syst., 29: 561-571.
Naoto, Y., P. Ardyono and Z. Yoshifumi, 2008. A novel method for transient stability analysis as boundary value problem. Proceedings of the International Conference on Electrical Engineering (ICEE), July 6-10, 2008, Okinawa, Japan, pp: 1-6.

Pagani, G.A. and M. Aiello, 2016. From the grid to the smart grid, topologically. Physica A. Stat. Mech. Appl., 449: 160-175.

Rahman, M.S., M.A. Mahmud, H.R. Pota and M.J. Hossain, 2015. A multi-agent approach for enhancing transient stability of smart grids. Intl. J. Electr. Power Energy Syst., 67: 488-500.

Rahman, M.S., M.J. Hossain and H.R. Pota, 2012. Agent based power system transient stability enhancement. Proceedings of the 2012 IEEE International Conference on Power System Technology (POWERCON), October 30-November 2, 2012, IEEE, Auckland, New Zealand, pp: 1-6.

Ramirez, E.S. and P. Villafuerte, 2016. Effect of the control of generators and Turbines on the Transient stability of a power system. IEEE. Latin Am. Trans., 14: 1227-1234.

Shi, J., Y. Tang, Y. Xia, L. Ren and J. Li etal., 2012. Energy function based SMES controller for transient stability enhancement. IEEE. Trans. Appl. Supercond., 22: 5701304-5701304.

Sulistiawati, I.B., A. Priyadi, O.A. Qudsi, A. Soeprijanto and N. Yorino, 2016. Critical clearing time prediction within various loads for transient stability assessment by means of the extreme learning machine method. Intl. J. Electr. Power Energy Syst., 77: 345-352.

Treinen, R.T., V. Vittal and W. Kliemann, 1996. An improved technique to determine the controlling unstable equilibrium point in a power system. IEEE. Trans. Circuits Syst. I. Fundam. Theory Appl., 43: 313-323.

Yorino, N., A. Priyadi, H. Kakui and M. Takeshita, 2010. A new method for obtaining critical clearing time for transient stability. IEEE. Trans. Power Syst., 25: 1620-1626.

Yorino, N., Y. Kamei and Y. Zoka, 2005. A new method for transient stability assessment based on critical trajectory. Proceedings of the 15th International Conference on Power System Computation (PSCC), August 22-26, 2005, Liege, Belgium, pp: 1-6.

Zhang, F. and C.S. Cheng, 1997. A modified Newton method for radial distribution system power flow analysis. IEEE. Trans. Power Syst., 12: 389-397. 